\title{
Exploration Research of Teaching Mode Based on Micro Lesson and the Flipped Classroom
}

\author{
Jinzhong Liu \\ Qiqihar Medical University, Qiqihar, Heilongjiang Province, China
}

Keywords: Micro classes, Flipped classroom, teaching model, exploring research

\begin{abstract}
Micro and flipped classroom teaching method are the rises in recent years. In the flipped classroom for learners to build a personalized collaborative learning environment, contribute to the formation of the new learning culture. By surrounding the origin flipped classroom, the concept and characteristics of analysis, based on the inversion theory classroom, we construct a micro classroom teaching model, and analyzes the flip Micro classroom challenges the process of facing the implementation, with a view to our Teaching for reference.
\end{abstract}

\section{Introduction}

Traditional teaching process typically includes knowledge transfer and within the knowledge of the two phases. Imparting knowledge is taught by teachers in the classroom to complete, within the knowledge of the needs of students in after-school through the job, operation or practice to complete [1]. On the flipped classroom, this form has been subverted by imparting knowledge of information technology supporting the completion of the class, knowledge is internalized by assisting in the classroom to help teachers and students accomplished, thus forming a flipped classroom. With the reversal of the teaching process, classroom learning process in all aspects also will be changed. The main case of the traditional classroom and flipped classroom each element of contrast.

Micro lessons and flip the classroom teaching method is the rise in recent years, then the two teaching methods on what kind of promotion and improve the practical teaching, and how to design and production, through the analysis of our entries and we together to discuss the effect of actual use.

\section{The characteristics of the micro teaching}

First: "micro class" with China since 2012 is a form of network video short courses, according to the ministry of education of the national education in colleges and universities is the definition of network training center: 10-20 minutes video as the main carrier, record teachers around certain knowledge or teaching conduct short, complete the teaching activities. Turn [1] in the training class, according to the concept of the system of teaching theory, we suggest that the "class" of recording time in 10 minutes, there is a clear teaching goal, content of short, concentrated shows a small problem of course. A "little video" needs and learning, students' learning activities combined process and so on, is a complete lesson "micro"; If left the students' learning activities, just a recording of the content of the teacher in class teaching activities, the essence is a video recording of class teaching activity, can be used as a learning material, not form a "class" system. Therefore, the evaluation standard of "course", need to include teachers teaching the teaching content of micro video, also including the arrangement of single and students learning activities.

The design of the micro lessons. "Why" micro courses to within 10 minutes of video time?This is according to khan courses abroad and brain science research, the average person in 10 minutes or so the duration of your attention. Micro class time is in commonly $3 \sim 5$ minutes to be beautiful, more than 6 minutes, people can watch video is feeling a bit tedious. Need of special note is, the course is mainly to use "little video" as the media of record teachers teach knowledge skills, teachers can also, according to the requirements of different disciplines and teaching situation in other ways, such as audio (sound), such as PPT, text format of the media, not necessarily confined to the video format. 
How to design good is suitable for the micro course of students' autonomous learning, this matter in our micro courses for teachers to find some front-line teachers during has just started to learn the course of time, often the class design becomes the courseware, no master students need what kind of courses. It reflects most of the teachers have been formed for a long time is given priority to with teaching of "computer aided teaching" mind-set. Therefore, the process of learning by using micro actually is teachers change the teaching idea, grasp the new way of teaching and the teaching strategy of information age. In the process of the transformation, the teachers first oneself want to learn the course design and production methods.

Reallocation of classroom time. "Class" is the "traditional" curriculum enrichment or fragments of the video. So in addition to facilitate display communication, micro lessons worth?After reviewed some relevant background information, the author gradually to the value of the micro class have a more in-depth understanding, it is not only a convenient communication, combined with flip class is more of a change in the pattern of traditional classroom after trying. Recent "flip" classroom is familiar with the open education movement initiated in recent years, the United Nations educational, scientific and cultural organization, as well as the subsequent line is close to the massive open online course movement, so the lesson of the connotation of teaching communication so far more than simple.

Flipped classroom of second core feature is to reduce the time teachers teach in the classroom, leaving students more time learning activities. These learning activities should be based on real life, real situations, and allows students to complete learning tasks in interactive collaboration [1]. The original content of classroom teaching to the next lesson, without reducing the amount of basic knowledge demonstrated on the basis of high school students enhance classroom interaction. Ultimately, the change will increase the students' understanding of the extent of the knowledge. In addition, when teachers based on performance evaluation, classroom interaction will become more effective. According to the evaluation feedback of teachers and students will be more objective understanding of their own learning, better control of their own learning.

\section{Teaching mode of micro class with flip classroom}

Flip the first class began in Woodland Park, Colorado high school, by Jonathan barman and Aaron sums. This home through online lectures and small class teaching video content of autonomous learning, to school face-to-face teaching and answering questions, adding out front of study way, allowing the use of micro class vitality to continue. China's earliest flip Guangdong stone bridge primary school classroom.

In the new "flip" classroom teaching process, teachers for students' autonomous learning teaching "little video" is the "small class" became a indispensable important part of students' autonomous learning. Flip the classroom processes are: teachers have "warm up" effect of questions; Students watch video of autonomous learning, solve the problem of teachers; Students practice feedback, identify problems; Teachers collect problem, around teaching target, interaction and meaning. Turn over the main points of the class is: around teaching target, to the point; Demonstrate knowledge of occurrence, development, application, the relationship between the; Use inductive thinking more, a little less deductive thinking; As far as possible let students conclude, teachers inspiration and extension; The suspected thought, the source of thought is the foundation of the think tank; Doubt is the machine of consciousness, consciousness, to grow. Flip is the advantage of classroom: starting to teach me to learn to teach from passive learning to active learning, lets the student is directly facing the opportunity of new content, new problems and new situation, and on the basis of self-study understanding, through a variety of interactive training depth, critical thinking, make knowledge into long-term memory. Flip class benefited from the rapid development of modern science and technology, absorbed from global knowledge of video interpretation, so that the students through independent learning really become an idea of the strong, adapt to the trend of lifelong learning.

The combination of micro class and flip. The implementation of the "flip" classroom, combining with study on "independent charge, the teacher in charge, no one to take charge of" the theory of "three" such as with reinforcement, the consciousness of the students' self-study consciousness 
especially prepare intensification. Major changes have taken place in most of the teachers' classroom mode, cut to the chase of teaching, to the point, obviously improve the classroom efficiency.

Micro class as the core, with the auxiliary element such as practice, feedback, examination, has formed a kind of teaching method, subverts the traditional teaching concept system is also be used for reference.

Teaching always inseparable from knowledge to knowledge internalization to undertake two natural processes, the traditional teaching of knowledge takes place in a formal classroom, while in extra-curricular knowledge internalization. The so-called "flip" class is changing the scene, let the students self-study before class, and the formal class time teachers responsible for answering questions, to help students complete the internalization of knowledge. The role of micro lesson here is to replace teachers help students completing the process of knowledge in the study. Not only the time and place of the two processes, the teacher's role is from the original knowledge to assist students' knowledge internalization. The students' learning freedom, knowledge internalization of obstacles greatly reduced due to the teacher's help. In fact, formal classroom knowledge take up teachers a lot of time and effort, the traditional teaching mode is indeed widespread after-school tutoring teachers lack the phenomenon. Flip the classroom to let the students extra-curricular knowledge itself, classroom teachers coaching answering it overturns the traditional teaching mode, but the actual effect is highly dependent on the student self-learning ability, as well as the teachers of open courseware design and feedback to the student's full attention. In ordinary teaching scale, flip the classroom for teachers and students both sides is not less than the traditional classroom, into energy and turn the classroom students less the scene of the teachers' guidance in the process of self-study, if video courseware explanation does not reach the designated position or students self-study ability is weak, will cause the difficulty of knowledge stage. Therefore, the traditional teacher-centered classroom, turn and student-centered classroom each have advantages and disadvantages as mentioned above, flip the classroom more teachers spend a lot of energy for design is suitable for the teaching process, students' self-study in the teaching of general scale its advantage is not fully embody.

Micro classroom activities Module Design. Micro class is different from traditional online public class, between teachers and students, students can be interactive, can communication on the Internet, students front doubts can solve face to face in the classroom, can also be in the online classroom online communications. When micro lessons for students can choose the teacher in class, follow one's inclination sly to that, little mouse, and can be autonomous learning. As the online classroom is becoming more and more mature and perfect, there will be real "without walls" free school resources more rich and more attract learners, thus forming the sustainable development of the MOOC, very significance.

One of the features Flip Micro classroom is carried out on the basis of maximizing, continue to extend the classroom learning time to improve learning efficiency, the key is within the knowledge of how to accomplish through classroom activities designed to maximize [4]. Constructivists believe that the acquisition of knowledge in certain situations learners meaning construction process of realization through interpersonal collaboration activities. Therefore, teachers in designing classroom activities, should take full advantage of situation, cooperation, conversation and other factors into full play the subjectivity of students to complete the current internalize what they have learned (see fig. 2).

Depending on the selected group of Students, when the problem involves a broader and can be divided into several sub-problems, team members can follow the "Puzzle" Learning to explore learning. Each team member is responsible for a child to explore the issue, and finally the overall polymerization together for collaborative inquiry. When the problem involves a small, not easy to be divided, each team member can be an independent study of the issue, and finally explore collaboration. 


\section{Learning Pyramid}

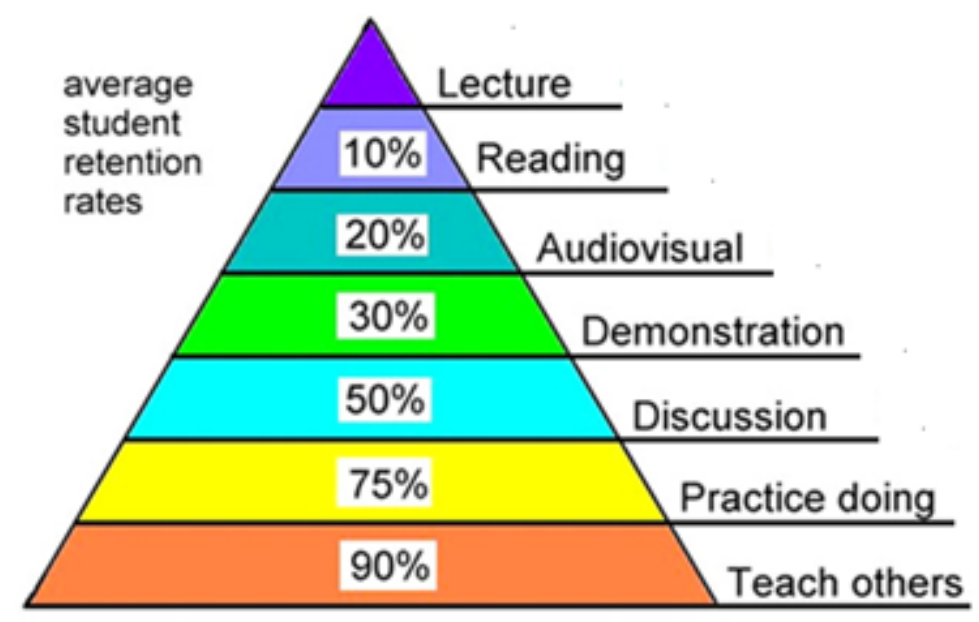

Fig. 1 Flipped classroom learning pyramid

1) Independent exploration. Independent learning ability is one of the important qualities of learners should possess. Individuals from a development perspective, the students are from dependence to independence process. Teaching wild country famous experts believe that students "independence" has four meanings [5]: a. Each student is an independent person, student learning is their own thing, this is not a substitute teacher is not replaced. Teachers can allow students to read their own feelings of things, observation, analysis, reflection, and help them self sensible, to acquire knowledge; b. are independent of each student teacher's mind, not to the teacher's will. Teachers want students to accept their teachings, first students should not exist as an objective in its own will as to transfer, as a person with independence to look at, so that their education to meet their actual situation; c. each student has an independent claim, the learning process in their school is a separate and independent process for growing. d. Each student (except for special reasons) has a very strong independent learning ability.

2) Identify problems. Teachers need to watch instructional videos based on course content and students before class practice raised questions, summed up some questions worth exploring. Students choose the appropriate topic based on understanding and interest inquiry. In this process, teachers should be targeted to guide students in selecting topics [4].

3) Achievements exchange. Students through independent exploration, collaborative learning after completion achievement highlights individual or group. Students need to be reported in the classroom, the exchange of learning experiences, to share the joy of success and the work produced [6]. The forms can be varied outcomes exchange, such as holding exhibitions, lectures, debates, and other small game.

In addition to reporting directly in the classroom, it can also flip the reporting process, the students in their spare their reporting process for video, uploaded to the network platform, teachers and students in reporting after watching the video, in class discussion and evaluation.

4) Collaborative Learning. Collaborative learning is the use of dialogue between individuals, discuss, debate and other forms fully demonstrated by the research questions to get way to achieve learning objectives [5]. In addition, the formation of collaborative learning students 'critical thinking and creative thinking, improve students' communication skills, self-esteem and mutual respect form the relationship between the individual, have a significant positive effect. Therefore, the classroom should be flipped Micro interactive learning designed to enhance collaboration.

Micro flipped classroom interactive activities, teachers need to capture the students to be dynamic and timely guidance. The Panel is an interactive course of basic building blocks, its interaction involving 2 or 2-5 people. Advantage flipped classroom environment group cooperation: everyone can participate in activities; and to allow and encourage students to low-risk, non-threatening way to participate meaningfully; may provide an opportunity for participants to communicate with their 
peers, and are free check the correctness of their own ideas; providing a variety of strategies to solve the problem, brainstorming.

5) Feedback Assessment. Flip Micro classroom assessment and evaluation system is completely different from the traditional classroom. In this teaching model, the evaluation should be completed by the experts themselves, academics, teachers, peers and learners. Flip Micro classroom should not only focus on learning outcomes assessment, but also through the establishment of student learning archives, focusing on the evaluation of the learning process, truly quantitative evaluation and qualitative evaluation, formative assessment and summative evaluation, personal evaluation and the evaluation team, a good combination between self-assessment and evaluation of others [6]. Content evaluation of the issues involved choice, independent of the performance of the learning process, learning in the group's performance, study schedule, schedule, results and other aspects of expression and the results show. Evaluation of the results emphasize the students' knowledge and skills mastery, process evaluation emphasized that students in the experimental record, all kinds of raw data, activity log form, questionnaire, interview table, learning experience, reflect on the contents of the diary and other performance .

\section{Conclusion}

Flipped class and micro class have formed the current hot spots, precisely because they fully adapted to the current knowledge explosion time background of mobile digital life. We should fully understand their history and connotation, not constrained specific content form copycat hype, but should fully absorb and make use of the characteristics of these two kinds of new teaching methods, on the one hand, the excavation of the campus students interest in learning, improve the quality and efficiency of teaching and learning; On the other hand, through the careful design organization, increase the rate of regional social sharing of education resources, for the improvement of expanding education and social education fair chance opportunity to do my best.

\section{Acknowledgement}

2016 medical education research project topic of "Medical education branch of Chinese medical association" and "Medical education professional committee of China's higher education institute", (Project No. 2016B-FF054).

\section{References}

[1] Zh. Y. Guo, Y. J. Zhang, Perspective of "flipped classroom",Primary and Secondary Schools IT education, 2012,pp. 21-27.

[2] J.H.Li, Meaning and development of micro class, information technology education of primary and secondary schools, 2013, vol.4, pp. 21-27.

[3] J.L. Zhang and B.H.Zhang, The flippedclassroom teaching mode study, Journal of distance education, 2012, pp. 55-58.

[4] M Z.X. Zhang,Micro lessons and classroom discussion on,University education, 2013, vul.12, pp. 33-36.

[5] R.Y. Xiong, Teacher Notes "flip" the language classroom, Primary and Secondary School Information Technology Education, 2014, pp. 91-95.

[6] L.J. Wang, Experience Review MIT OCW use project, Open Education Research, 2005, pp. 43-48. 